\title{
What Influences Citizens' Expectations towards Digital Government? An Exploratory Survey
}

\author{
Anthony Simonosfki ${ }^{a, b}$, Antoine Clarinval ${ }^{a}$, Benoît Vanderose ${ }^{a}$, Bruno Dumas ${ }^{\mathrm{a}}$, Monique \\ Snoeck ${ }^{\mathrm{b}}$ \\ ${ }^{a}$ Namur Digital Institute, University of Namur, Belgium \\ ${ }^{b}$ Faculty of Economics and Business, Katholieke Universiteit Leuven, Belgium
}

\begin{abstract}
Purpose - Governments around the world engage in digitalization projects to improve their internal functioning and the delivery of information and services to their users, including citizens. There are several ways to implement this digitalization and, therefore, different roles for citizens, who can be considered as customers, as participants, and as coproducers in a digital government. The purpose of this study is to identify which factors influence the roles citizens are willing to take in a digital government.

Design/methodology/approach - We conducted a exploratory survey in Belgium. We examined which factors among age, gender, occupation, education, digital literacy, government level, and frequency of use of other e-services influence citizens' roles.

Findings - Through to a statistical analysis conducted on data collected from 203 citizens, we identify 25 relationships between the aforementioned factors and expectations mapped to the citizens' roles. We have identified relationships between expectations and government level, gender, age, occupation, use frequency of other e-services, and digital literacy. On the other hand, we found no influence for the education level and for working in an administration.

Originality - No previous work has asked directly to citizens which role they would be willing to take and, consequently, what expectations they have towards digital government. We contribute a usable survey instrument to achieve this and we have demonstrated how it can be used to collect data from citizens. In doing so, we contributed valuable findings supporting Belgian policy-makers in developing digital government policies that are aligned with citizens' expectations.

Research limitations/implications - This study contributes to the research field by providing insights into what citizens expect from digital government and exploring several relationships to be investigated in further research.
\end{abstract}

Key words: Citizen, Digital Government, Expectations, Survey

Email addresses: anthony.simonofski@kuleuven.be (Anthony Simonosfki), antoine.clarinval@unamur.be (Antoine Clarinval), benoit.vanderose@unamur . be (Benoît Vanderose), bruno.dumas@unamur.be (Bruno Dumas), monique.snoeck@kuleuven.be (Monique Snoeck) 


\section{Introduction}

New advances in Information and Communication Technologies (ICT) have enabled numerous organizations to rethink and improve their processes. Digital government refers to the use of ICT by administrations to improve their internal functioning and the delivery of information and services to its users (i.e.citizens, business partners, employees, and other government entities) Andersen and Henriksen, 2006; Gil-Garcia et al., 2018. Digital government promises numerous benefits for both the administrations and their users Foley and Alfonso, 2009. On the administration side, examples include agility, efficiency, and increased service quality Alenezi et al., 2017]. On the user side, reported benefits include time and money gain Gilbert et al., 2004.

Among the different types of users, citizens have always benefited from a particular attention both from researchers and practitioners. Numerous papers have examined which factors influence the citizens' intention to use e-government services, such as perceived usefulness, compatibility, perceived ease of use, and trust in government Horst et al., 2007; Hung et al., 2006; Bélanger and Carter, 2008; Kurfalı et al., 2017; Hamid et al., 2016; Naranjo-Zolotov et al., 2019. However, the changing paradigm of digital government implies a changing role of citizens in the processes. Some papers consider citizens as passive recipients of services whereas others consider them as active participants in public processes Lawson-Body et al., 2014; Simonofski et al., 2017b. The type of implemented digitalization, as well as the intended role for citizens, heavily depends on the values targeted by the administration Jaspers and Steen, 2019; Simonofski et al., 2020], such as efficiency, customer relation, or participation. Scholars also discuss conflicting views about what digital government should be. Lawson-Body et al. [2014] detail two streams of research in e-government: electronic democratization theorists link e-government to participation while economics theorists focus on efficient and effective service delivery. Yildiz 2007] discuss the evolution of citizens from passive actors to active actors in digital government. Tolbert and Mossberger 2006 distinguish two orientations for digital government: entrepreneurial, which is customer and service oriented, and participatory, which focuses on accountability, transparency, and responsiveness.

Given the multiple existing orientations of digital government, we consider it as a multifaceted concept characterized by different roles citizens can take in the digitalization, depending on how it is implemented. However, no previous work has asked directly to citizens which role they would be willing to take and, consequently, what expectations they have towards digital government. Indeed, even though interesting efforts have been made to identify the users of digital government and to provide a typology for these users Distel and Becker, 2017; Distel and Lindgren, 2019], a study identifying which factors influence these expectations and how they do remains needed in the current scientific literature. Therefore, in this paper, we aim at filling this gap by asking directly to citizens via an exploratory survey what they expect from the digitalization of governments. In doing so, we aim at answering to the following research question:

Which factors influence the roles citizens are willing to take in a digital government? 
Given the potential breadth of expectations, and in order to focus the analysis, we identified potential types of expectations from broader categories identified in literature. These refer to three typical roles of citizens in the digital government literature: citizens as customers, as democratic participants, and as coproducers. On the factors side, we investigated government level, age, gender, education level, occupation, being employed by an administration, digital literacy, and frequency of use of private and public e-services and of social media. We devised a survey instrument structured around the three roles and the ten factors to understand which role citizens prefer and which factors influence this preference. The data collected from 203 citizens allowed identifying 25 relationships between the factors and the roles, for which we provide statistical evidence. Understanding which roles citizens expect to have in a digital government will be helpful for researchers at it formalizes relationships to be investigated in further research. Moreover, it is valuable for policy-makers, as they can adapt their digital government strategy depending on the distribution of expectations of citizens so that it is customer-oriented, participation-oriented, or coproducer-oriented.

This paper is structured as follows. Section 2 introduces the different concepts and related work this study builds on. It specifically focuses on the three aforementioned roles and how we derived the expectations from these roles. Section 3 presents the research design used to gather and analyze the data from the citizens. Section 4 presents the result of the survey by providing descriptive statistics and identifying relationships between factors and citizens' expectations. In Section 5, we reflect on the results, discuss the limitations of the research, elaborate some leads for further research, and detail the relevance of the research to policy-makers. Section 6 provides some closing comments to the paper.

\section{Background}

As mentioned above, there are multiple views on how digital government should be defined in research and implemented in practice, and thus on the different possible roles for citizens. Previous research has already formalized these different roles. In this paper, we will rely on the categories identified in a previously performed systematic literature review $\mathrm{Si}$ monofski et al., 2017b]. We chose these categories as they are consistent with other formalizations of citizens' role in digital government Berntzen and Johannessen, 2016; Callahan, 2007; Simonofski et al., 2017a. Indeed, these studies separate the role of "customers" and "participants" for citizens, as underlined in the introduction. Furthermore, within the "participants" role, they also differentiate between the participation in democratic life and the coproduction of public services. The three roles retained in this paper are thus the following:

Citizens as Customers: citizens are considered as recipients of digital government services. Thus, in this role, digital government refers to the actions taken to improve service quality, efficiency, and effectiveness thanks to ICT to increase citizens' satisfaction (e.g. citizen relationship management system). This role is further described in West, 2005; Veiga et al., 2016; Eyob, 2004.

Citizens as Democratic Participants: citizens are considered as active participants in the decision-making processes of government. Thus, digital government refers to the 
actions performed, with the help of ICT, to facilitate the impact of citizens in decisionmaking (e.g. e-voting systems). This role is further described in Porwol et al., 2016, Sundberg, 2019; Macintosh, 2004].

Citizens as Coproducers: citizens are considered as holders of ideas and expertise that can assist governments in their daily tasks. This assistance can take place in the development of a digital government service (e.g. communication of requirements), or through the help of an existing digital government service (e.g. FixMyStreet $[\mathrm{Pak}$ et al. 2017]). This role is further described in [Simonofski et al., 2019; Axelsson et al., $2010]$.

While these different roles have already been discussed by other authors from different research fields, to our knowledge, no work has reported on a study asking directly to citizens what they expect from a digital government (in other words, which roles they are willing to take on) and identifying which factors influence their expectations. However, several previous studies have performed research in a similar direction. In their analysis of the motivations of citizens to participate, Wijnhoven et al. [2015] have conducted a survey to better understand which dimensions influence citizens. Furthermore, Distel and Becker 2017] suggest to investigate in a deeper way the abstract "citizen" concept, attempting a segmentation of the population in relation with e-government services use. Naranjo-Zolotov et al. [2019] reported on the results of a survey research studying citizens' motivations to use e-participation platforms. More recently, Choi and Song [2020] explored the factors influencing the engagement of citizens in e-participation. In this paper, we engage further in the direction of these related papers by investigating which roles citizens would be willing to take in digital government and which factors influence their preferences.

\section{Research Design}

\subsection{Research Model and Research Questions}

The goal of the research is to determine the factors influencing the roles citizens are willing to take in digital government. Thus, at the center of our research model is a dependent variable measuring citizens' willingness to take on the defined roles. The factors of which we study the influence are the independent variables. Since there is no previous work identifying the factors impacting citizens' willingness to take on these roles, we performed a broad search for studies published in the field of digital government with a research design similar to ours. The found studies focus on the use or intention to use of digital government services. They allowed identifying ten factors that were relevant to our research question.

For each factor, Table 1 provides the related studies it was extracted from, details the rationale behind its inclusion in this study, and maps it to a research question studying its impact on the roles citizens are willing to take in digital government.

\subsection{Questionnaire Design}

In order to collect the data needed to answer the research questions, we conducted a survey through a questionnaire distributed following a multi-channel strategy. We formulated several statements based on the literature discussed in Section 2. In order to capture insights into RQ1, the statements were investigated for both the local and the federal/regional 
Table 1: Factors included in the research model.

\begin{tabular}{|c|c|c|}
\hline $\begin{array}{l}\text { Research } \\
\text { question }\end{array}$ & Factor & Rationale \\
\hline RQ1 & Level of government & $\begin{array}{l}\text { The study takes place in Belgium, a country that has a multi-level } \\
\text { governance setting Bache et al. } 2016 \text {. We therefore distinguish } \\
\text { between the local and regional/federal levels }\end{array}$ \\
\hline RQ2a & Gender & $\begin{array}{l}\text { Factor studied in Wijnhoven et al. 2015, Rodrigues et al. } 2016 . \\
\text { Voutinioti, 2013 }\end{array}$ \\
\hline RQ2b & Age & Factor studied in Wijnhoven et al. 2015 Voutinioti 2013 \\
\hline RQ2c & Education & $\begin{array}{l}\text { Factor studied in Wijnhoven et al. 2015, Rodrigues et al. } 2016 \text {, } \\
\text { Voutinioti, 2013 }\end{array}$ \\
\hline RQ2d & Occupation & Factor studied in Wijnhoven et al. |2015| \\
\hline RQ2e & Administration & $\begin{array}{l}\text { We set a particular focus on employment in administration as pub- } \\
\text { lic servants can have a different view towards their expected role in } \\
\text { digital government due to their job in the administration Baldwin } \\
\text { et al. } 2012\end{array}$ \\
\hline RQ3 & Digital literacy & $\begin{array}{l}\text { Previous research showed influence of digital literacy in the con- } \\
\text { text of digital government implementations [Nawafleh, } 2018\end{array}$ \\
\hline $\begin{array}{l}\text { RQ4a } \\
\text { RQ4b } \\
\text { RQ4c }\end{array}$ & $\begin{array}{l}\text { Private e-services use } \\
\text { Social media use } \\
\text { Public e-services use }\end{array}$ & $\begin{array}{l}\text { Previous research showed a link between the use of other e-services } \\
\text { and the use of public e-services use Bélanger and Carter, 2009, } \\
\text { Rodrigues et al., 2016, Voutinioti, 2013 }\end{array}$ \\
\hline
\end{tabular}

government levels. Thus, for each statement, respondents had to give their opinion for their city and for their region/country. On a general note, the basis intuition was that several statements would stimulate positive answers from the respondents ( $\mathrm{S} 1$ in particular), but the goal of this questionnaire is to analyze to which extent people agree with the statements and which factors influence the answers' distribution. The following statements were included in the questionnaire:

S1: You wish the electronic public services of your [city-region/country] were more accessible, faster, and more integrated with other levels of authority

S2: You would be willing to pay extra money (directly or through taxes) so that the electronic public services of your [city-region/country] are more accessible, faster, and more integrated with other levels of authority

S3: You would take time to consult relevant information about your [city-region/country] if they were available

S4: You would take time to use an online platform to participate in the democratic processes of your [city-region/country] if such a platform existed

S5: In exchange for a greater time investment on your part, you would favor the use of public electronic services if it reduced your [city-region/country]'s administrative burden

S6: You would take time to send relevant information to your [city-region/country]'s departments through an online platform if such a platform existed 
S7: You would take time to participate in the development of your [city-region/country]'s electronic public services if you were given the opportunity

S1 and S2 were derived from the Citizens as Customers role. We formulated S1 to capture the expectations related to the efficiency of the public e-services based on the vision of digital government presented in West, 2005; Veiga et al., 2016; Eyob, 2004]. Furthermore, we added $\mathrm{S} 2$ to check if the citizens were ready to pay for better public e-services, in a similar fashion to the freemium business model of some private e-services [Kumar, 2014].

S3 and S4 were derived from the Citizens as Participants role. S3 was added as information is an essential precondition for participation Arnstein, 1969 and is in line with the principles of Open Government [Janssen et al. 2012]. S4 was formulated around the most popular channel for e-participation in Belgium [Simonofski et al., 2019]: an online platform.

S5, S6, and S7 were derived from the Citizens as Coproducers role. S5 was formulated based on the proactive role that citizens can take to help governments in the execution stage [Linders, 2012]. S6 was created due to the popularity of applications and platforms to help send information to government (such as FixMyStreet [Pak et al., 2017]). Finally, S7 captures the time citizens can take to help public agents in the development of public e-services as reported in Simonofski et al., 2019; Axelsson et al., 2010.

Citizens' agreement with the statements was measured using a 5-point Likert scale ranging from "Totally Disagree" to "Totally Agree". Furthermore, the statements were pretested with a diverse group of 10 citizens to test the understandability of the statements and the time completion of the questionnaire.

Besides the statements, we added questions about socio-demographic status, public and private e-service and social media use frequency, and digital literacy. For the digital literacy, we relied on the research instrument provided in Hargittai, 2005; Hargittai and Hsieh, 2012; Hargittai, 2009]. It consists in measuring digital literacy by asking the respondents to rate their understanding of 9 concepts on a 5-point Likert scale ranging from "No understanding" to "Full understanding". The full questionnaire can be found in the supplementary material of this paper ${ }^{1}$.

\subsection{Data Collection}

We applied a multi-channel strategy for data collection in order to avoid bias induced by the lack of access to digital tools of some respondents. We put the questionnaire online, presented it through social media and on four local communities websites. Furthermore, we also printed paper versions of the questionnaire and conducted face-to-face interviews in the cities of Brussels, Namur and Charleroi (Belgium). The data collection phase lasted from June 2019 to October 2019. The completion time of the questionnaire ranged between 10 and 15 minutes per respondent with no excessive deviation from this average. This absence of outliers did not force us to remove poor quality responses from the dataset Malhotra, 2008]. The data collected is available in open access for reuse by other researchers ${ }^{2}$,

The data collection strategy is thus based on convenience sampling [Etikan et al., 2016]. Despite some limitations such as the potential lack of representativeness, convenience sam-

\footnotetext{
${ }^{1}$ Available at: https://zenodo.org/record/4041220\#.X2iqKWgzY2w

${ }^{2}$ Available at: https://zenodo.org/record/4045328\#.X2r3d2gzY2w
} 
pling has been applied in digital government studies in the past [Wijnhoven et al., 2015; Voutinioti, 2013; Meftah et al., 2015; Kaur and Rashid, 2008; Ahmad et al. [2013]. Furthermore, we consider it sufficient given the exploratory nature of our study. As advised by Etikan et al. [2016], we compared the output of the convenience sampling with the proportions describing the general population in Belgium collected from official Belgian governmental sources. Table 2 shows a comparison between the sample from which we collected data and a theoretical perfectly representative sample of the Belgian population.

Table 2: Description of the surveyed sample and comparison with a theoretical sample defined by the numbers derived from official Belgian census data.

\begin{tabular}{|c|c|c|c|}
\hline Characteristic & Sample & Population & Representativity \\
\hline Gender $^{I I}$ & & & \\
\hline Female & $92(45.3 \%)$ & $104(51 \%)$ & - \\
\hline Male & $111(54.7 \%)$ & $99(49 \%)$ & - \\
\hline $\operatorname{Age}^{T 2}$ & & & - \\
\hline$<20$ years & $21(10.3 \%)$ & $14(6.9 \%)$ & over \\
\hline 20-29 years & $81(40.0 \%)$ & $30(14.8 \%)$ & much over \\
\hline 30-39 years & $26(12.8 \%)$ & $30(14.8 \%)$ & - \\
\hline 40-49 years & $30(14.8 \%)$ & $35(17.2 \%)$ & - \\
\hline 50-59 years & $24(11.8 \%)$ & $34(16.7 \%)$ & under \\
\hline$>60$ years & $21(10.3 \%)$ & $60(29.6 \%)$ & much under \\
\hline $\begin{array}{l}\text { Education } \\
\text { level }^{T 3}\end{array}$ & - & - & - \\
\hline Low & $7(3.4 \%)$ & $55(27.1 \%)$ & much under \\
\hline Medium & $69(34.0 \%)$ & $75(36.9 \%)$ & - \\
\hline High & $127(62.6 \%)$ & $73(36.0 \%)$ & over \\
\hline Occupation $^{T 4}$ & - & - & - \\
\hline Employed & $99(48.8 \%)$ & $93(45.8 \%)$ & - \\
\hline Self-employed & $14(6.9 \%)$ & $16(7.9 \%)$ & - \\
\hline Student & $67(33.0 \%)$ & $22(10.8 \%)$ & much over \\
\hline Unemployed & $6(3.0 \%)$ & $9(4.4 \%)$ & under \\
\hline Homemaker & $1(0.0 \%)$ & $9(4.4 \%)$ & much under \\
\hline Retired & $16(7.9 \%)$ & $54(26.6 \%)$ & much under \\
\hline Total & $203(100 \%)$ & $203(100 \%)$ & - \\
\hline
\end{tabular}

${ }^{T 1}$ Numbers from most recent decennial census (2011) in Belgium (available:

https://www.census2011.be/data/fresult/sexratio_fr.html)

$T^{2}$ Based on the age distribution in Belgium for 2017 (available:

https://statbel.fgov.be/en/themes/population/structure-population\#panel-11)

${ }^{13}$ The education levels reported by the Belgian government census are low, medium, and high. Low corresponds to an inferior secondary degree at maximum, medium to the superior secondary degree, and high to any degree higher than superior secondary (i.e. high school, university, PhD). Numbers reported by the Belgian government in 2017 can be found online: https://statbelpr.belgium.be/fr/themes/ emploi-formation/formation-et-enseignement/niveau-dinstruction\#figures

$T 4$ Based on the numbers reported by the Belgian government for 2017 (available: https:

//statbel.fgov.be/sites/default/files/files/documents/FR_kerncijfers_2018_web1a.pdf5 and https://statbel.fgov.be/fr/themes/emploi-formation/marche-du-travail/emploi-et-chomage\# panel-12)

It can be observed from Table 2 that the surveyed sample suffers from representativity issues, which can be explained by the questionnaire distribution channels. Overall, younger citizens and students are overrepresented while older and retired citizens are underrepre- 
sented. While the face-to-face interviews helped mitigating this issue, the social media distribution reached mostly younger citizens (and thus, logically, students).

\subsection{Data Analysis}

The research questions address the relationship between factors and agreement with statements related to the three roles defined for citizens in digital government. As agreement with these statements is measured on a 5-point Likert scale, the data collected for those is ordinal, which rules out the use of parametric statistical tests. In order to determine which statistical tests are adequate, the scale on which of the variables related to the factors are measured has to be considered. The adequate statistical tests were carefully selected from literature Malhotra et al., 2011; Gaddis and Gaddis, 1990; Schober et al., 2018 and also from studies with a similar research design mentioned in Section 3.1. The research questions involve statistical tests between ordinal variables and variables measured on several different scales. Therefore, we defined a test strategy for each scale combination as follows:

Dichotomous - Ordinal: The 2-sample Kolmogorov-Smirnov Pratt and Gibbons, 1981 test was used to compare the distribution of the dependent variable across the two groups defined by the independent variable (e.g. the distribution of answers given to S1 across males and females). If the test reveals a significant difference, visually examining the distributions allow determining the direction of the difference. This strategy was used for RQ2a (gender) and RQ2e (working in an administration).

Nominal (more than 2 groups) - Ordinal: The Kruskal-Wallis H test Kruskal and Wallis, 1952 was used to compare the distribution of the dependent variable across the groups defined by the independent variable (e.g. the distribution of answers given to $\mathrm{S} 1$ across occupation groups). If the test reveals a significant difference, a post-hoc analysis with Dunn's test Dunn, 1961 (with Bonferroni correction) can be performed to determine if there are pairwise differences across the groups. This strategy was used for RQ2d (occupation).

Ordinal — Ordinal: The Jonckheere-Terpstra test Jonckheere, 1954; Terpstra, 1952 was used to determine whether there is significant trend between the independent and the dependent variable [Bewick et al., 2004]. An example of such trend would be that citizens with higher degrees tend to agree more with one given statement. If the test reveals a significant difference, a post-hoc analysis with Dunn's test (with Bonferroni correction) can be performed to determine if there are pairwise differences across the groups. This strategy was used for RQ2b (age), RQ2c (education level), and RQ4 (e-service use frequency).

Continuous - Ordinal: The Jonckheere-Terpstra test was used to to determine whether there is significant trend between the dependent and the independent variable. For example, the test compares the distribution of digital literacy across the five groups defined by the five possible answers to $\mathrm{S} 1$ to determine whether respondents agreeing more with the statement tend to have a higher or lower digital literacy. If the test reveals a significant difference, a post-hoc analysis with Dunn's test (with Bonferroni correction) was performed to determine if there are pairwise differences across 
the groups. The groups thus defined are labelled TD (i.e. respondents who answered "Totally disagree"), D (i.e. respondents who answered "Disagree"), N (i.e. respondents who answered "Neutral"), A (i.e. respondents who answered "Agree"), and TA (i.e. respondents who answered "Totally agree"). This strategy was used for RQ3 (digital literacy). Indeed, a digital score could be measured for each respondent by averaging the answers given to the 9 questions on concept understanding, as Cronbach's alpha Cronbach, 1951] is 0.923 [Peterson, 1994]. Thus, the digital literacy score is withing the range of 1 (the respondent has answered "No understanding" for the nine concepts) to 5 (the respondent has answered "Full understanding" for the nine concepts).

As for RQ1 (government level), the answers given for the local and for the regional/federal government levels were compared pairwise, for each of the seven statements relating to the citizens' roles, in order to determine whether they tend to be similar. Spearman's rank correlation coefficient [Spearman, 1961] was used and interpreted following [Schober et al. 2018. In addition to this high-level comparison between the local and the federal/regional government levels, the finer-grained analysis of the answers to the statements in the other research questions can also highlight differences and similarities between these two levels. All tests were conducted with the IBM SPSS v26 software.

\section{Results}

In this section, we report on the significant relationships between the ten factors and the expectations of citizens we identified through our statistical analyses. A summary of the relationships is presented in Figure 1 and in Table 3 . An identifier Rx is assigned to each relationship and is referred to in the text describing it. For better readability, the information related to the 25 significant relationships (i.e. statistic value and significance level) are provided in Table 4 and 5 in the appendix. As they are more voluminous, the statistical details related to the post-hoc analyses as well as the visual representations of the analysis (bubble charts, box plots, bar charts) are available in the supplementary material document. An Excel spreadsheet summarizes the 25 relationships and gives the statistical details as well ${ }^{3}$.

\subsection{Government Level (RQ1)}

Spearman's correlation coefficient was computed pairwise for each of the seven statements as detailed in Section 3.4. All seven coefficients have a value of 0.685 or above and are statistically significant. Following interpretation guidelines from [Schober et al., 2018 this indicates that there is a significant strong positive relationship between the answers given for the local and the federal/regional government levels. This was confirmed by visually inspecting the findings with bubble charts, which show that respondents give highly similar answers for both government levels.

Thus, no significant influence of the government level on citizens' expectations was found. However, despite the absence of macro-level influence, smaller influences were identified

\footnotetext{
${ }^{3}$ Available at: https://zenodo.org/record/4041248\#.X2iqJ2gzY2w
} 


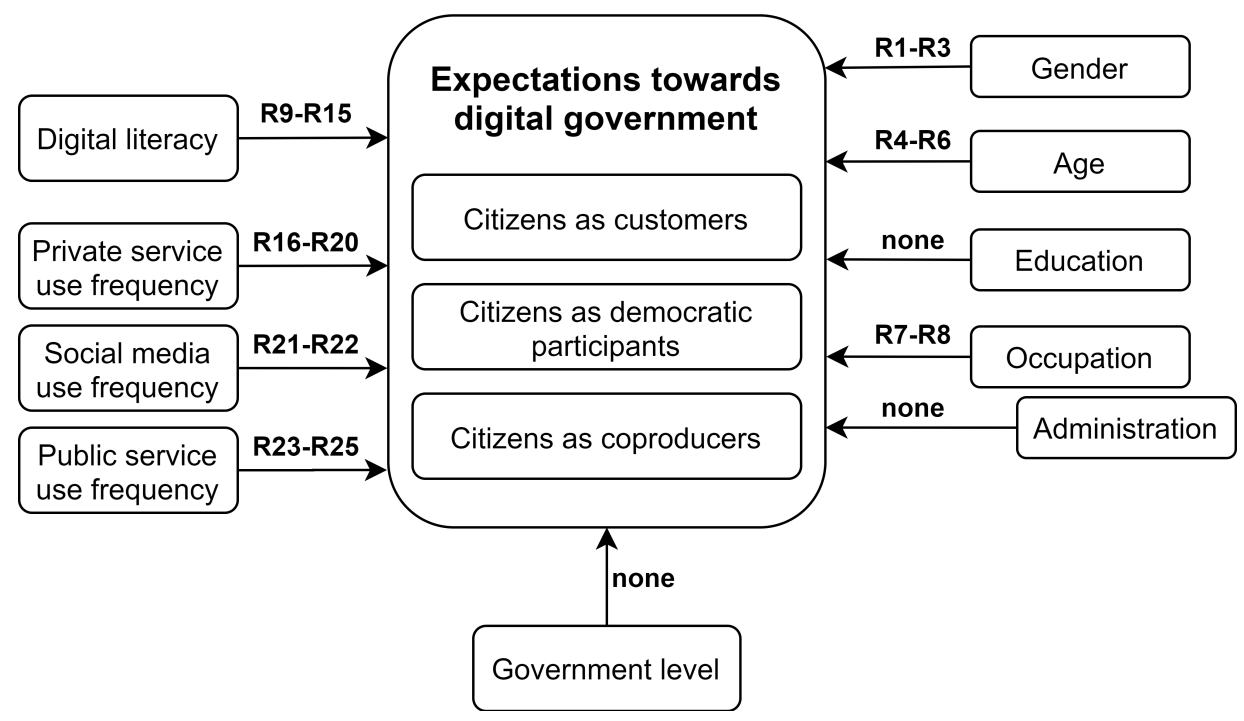

Figure 1: Summary of the observed relationships

between several statements and factors with respect to the government level they were linked with. These are described in the following subsections.

\subsection{Socio-Demographic Characteristics (RQ2)}

\subsubsection{Gender (RQ2a)}

The two-sample Kolmogorov-Smirnov test indicates whether the distributions of the answers to the statements differ significantly across the gender groups. However, it does not specify how they differ. In order to capture this information, the distributions for both gender groups were plotted on a comparative bar chart. For each statement for which a significant difference was observed, it allowed examining visually whether it is males or females who tend to agree more with the statement.

Males tend to be more in demand of faster and more integrated services (S1, R1) and more willing to take time to participate in the democratic processes through an online platform (S4, R2), for both government levels. In addition, males tend to be more willing to favor the use of public e-services to reduce the burden of the administration (S5, R3) for the local government level but not for the federal/regional.

\subsubsection{Age (RQ2b)}

Citizens in the 20-29 age group tend to be more willing to pay extra money for faster and more integrated services than those in the 50-59 group, for both government levels (S2, R4). Also, citizens in the 20-29 age group tend to be more willing to take time to participate in the democratic processes through an online platforms than those in the 40-49 and > 60 age groups, for both government levels (S4, R5). Finally, citizens in the 20-29 age group tend to be more willing to favor the use of public e-services to reduce the burden of the administration for the federal/regional level, but not for the local (S5, R6).

\subsubsection{Education (RQ2c)}

Our analysis showed no significant difference in the distribution of the answers across education level groups, for the seven statements. 


\subsubsection{Occupation (RQ2d and RQ2e)}

Only 1 of the respondents has the helper occupation, and 6 of them are unemployed. As these numbers are too low to study these two groups, they were sidelined from the analysis. Thus, the resulting sample holds 196 respondents divided among four occupation groups, namely student, employed, self-employed, and retired.

As for RQ2d (occupation), there is a significant difference across occupation groups for S3 (consult information), for both government levels. As for the local level, students tend to be less willing to take time to consult relevant information than employed and self-employed citizens. The post-hoc analysis revealed no significant pairwise difference for the federal/regional level (S3, R7). Also, retired citizens tend to be less willing to take time to participate in the democratic processes through an online platform than students and employed citizens, for both government levels. For the local level, retired citizens are less willing to participate in the democratic processes than self-employed citizens as well (S4, R8).

Concerning RQ2e (administration), 37 out of the 99 respondents in the employed group work in an administration. As explained in Section 3.4, the two compared groups are, on the one hand, citizens working in an administration, and, on the other hand, the other employed citizens. The analysis showed no significant difference in the distribution of the answers, for the seven statements.

\subsection{Digital Literacy (RQ3)}

Citizens who answered TA to statement S1 (better services) tend to have a higher digital literacy than those who answered TD, N, or A, for both government levels. In addition, citizens who answered $\mathrm{N}$ or $\mathrm{A}$ tend to have a higher digital literacy than those who answered TD, for the federal/regional government level (S1, R9). Citizens who answered N or A to statement S2 (pay for faster services) tend to have a higher digital literacy then those who answered D, for the local level. No significant result was observed for S2 for the federal/regional level (S2, R10).

As for the Citizens as participants role, citizens who answered TA to statement S3 (consult information) tend to have a higher digital literacy then those who answered A, for both government levels (S3, R11). Citizens who answered TA to statement S4 (democratic processes) tend to have a higher digital literacy then all others, for both government levels (S4, R12).

As for the Citizens as coproducers role, there is a trend of higher digital literacy with higher agreement to statement S5 (burden), for the federal/regional government level. However, there is no significant pairwise comparison. No significant result was observed for S5 for the local level (S5, R13). Citizens who answered TA to statement S6 (send information) tend to have a higher digital literacy than those who answered TD, D, or A, for both government levels. In addition, citizens who answered TA tend to have a higher digital literacy than those who answered N, for the federal/regional government level (S6, R14). Citizens who answered TA to statement S7 (participation in development) tend to have a higher digital literacy then all others, for both government levels (S7, R15). 


\subsection{Use of Other E-services (RQ4)}

\subsubsection{Private E-services use frequency (RQ4a)}

Citizens using private e-services daily or weekly tend to be more in demand of faster and more integrated public e-services than citizens never using them, for both government levels. In addition, citizens using private e-services daily or weekly tend to be more in demand of faster and more integrated public e-services than citizens using them yearly, for the local government level. Also, citizens using private e-services monthly tend to be more in demand of faster and more integrated public e-services than citizens never using them, for the federal/regional government level (S1, R16).

As for the Citizens as participants role, citizens using private e-services daily tend to be more willing to take time to consult relevant information than citizens using them weekly or never using them, for both government levels. In addition, citizens using private e-services weekly or monthly tend to be more willing to take time to consult relevant information than citizens never using them, for the local government level (S3, R17). Citizens using private e-services daily, weekly, or monthly tend to be more willing to take time to participate in the democratic processes through an online platform than citizens never using them, for the federal/regional government level. No significant result was observed for S4 for the local level (S4, R18).

As for the Citizens as coproducers role, citizens using private e-services daily tend to be more willing to take time to send relevant information than those never using them, for both government levels. In addition, citizens using private e-services weekly or monthly tend to be more willing to take time to send relevant information than those never using them, for the local level. Also, citizens using private e-services daily tend to be more willing to take time to send relevant information than those using them weekly, for the federal/regional level (S6, R19). Citizens using private e-services daily, weekly, or monthly tend to be more willing to take time to participate in the development of public e-services than citizens never using them, for both government levels (S7, R20).

\subsubsection{Social Media Use Frequency (RQ4b)}

There is a trend of higher agreement to statement S1 (better e-services) with higher social media use frequency, for both government levels. However, there is no significant pairwise comparison (S1, R21). There is also a trend of higher agreement to statement S4 (democratic processes) with higher social media use frequency, for both government levels. The post-hoc analysis showed that citizens using social media daily tend to be more willing to take time to participate in the democratic processes through an online platform than those never using them, for the federal/regional government level. There is no significant pairwise comparison for the local level (S4, R22).

\subsubsection{Public E-services Use Frequency (RQ4c)}

There is a trend of higher agreement to statement S1 (better e-services) with higher public e-service use frequency, for the federal/regional level. The post-hoc analysis showed no significant pairwise comparison. No significant result was observed for S1 for the local level (S1, R23). Citizens using public e-services weekly tend to be more willing to take time to participate in the democratic processes through an online platform than those using them yearly or never using them, for both government levels. In addition, citizens using 
public e-services daily tend to be more willing to take time to participate in the democratic processes through an online platform than those using them monthly, and citizens using public e-services monthly tend to be more willing to take time to participate in the democratic processes through an online platform than citizens never using them, for the local government level (S4, R24). Finally, there is a trend of higher agreement to statement S7 (participation in development) with higher public e-service use frequency, for the federal/regional level. The post-hoc analysis showed no significant pairwise comparison. No significant result was observed for S7 for the local level (S7, R25). 
Table 3: Summary of the observed relationships between factors and statements

\begin{tabular}{|c|c|c|c|c|c|c|c|c|c|c|c|}
\hline Role & Statement & $\begin{array}{c}\text { RQ1 } \\
\text { Govern. } \\
\text { level }\end{array}$ & $\begin{array}{l}\text { RQ2a } \\
\text { Gender }\end{array}$ & $\begin{array}{c}\text { RQ2b } \\
\text { Age }\end{array}$ & $\begin{array}{c}\text { RQ2c } \\
\text { Educa- } \\
\text { tion } \\
\text { level }\end{array}$ & $\begin{array}{c}\text { RQ2d } \\
\text { Occupat. }\end{array}$ & $\begin{array}{c}\text { RQ2e } \\
\text { Working } \\
\text { in admin- } \\
\text { istr. }\end{array}$ & $\begin{array}{c}\text { RQ3 } \\
\text { Digital } \\
\text { literacy }\end{array}$ & $\begin{array}{c}\text { RQ4a } \\
\text { Private } \\
\text { e-service } \\
\text { use }\end{array}$ & $\begin{array}{c}\text { RQ4b } \\
\text { Social } \\
\text { media use }\end{array}$ & $\begin{array}{c}\text { RQ4c } \\
\text { Public } \\
\text { e-service } \\
\text { use }\end{array}$ \\
\hline \multirow{2}{*}{ 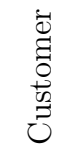 } & S1 & \multirow[t]{2}{*}{ - } & \multirow[t]{2}{*}{$\mathrm{R} 1$} & - & \multirow[t]{2}{*}{ - } & \multirow[t]{2}{*}{ - } & \multirow[t]{2}{*}{-} & $\mathrm{R} 9+^{*}$ & $\mathrm{R} 16+$ & $\mathrm{R} 21+$ & $\mathrm{R} 23+$ \\
\hline & S2 & & & $\mathrm{R} 4$-* & & & & $\mathrm{R} 10+$ & - & - & - \\
\hline \multirow{2}{*}{ 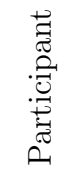 } & S3 & \multirow[t]{2}{*}{ - } & - & - & \multirow[t]{2}{*}{ - } & $\mathrm{R} 7$ & \multirow[t]{2}{*}{ - } & $\mathrm{R} 11+$ & $\mathrm{R} 17+$ & - & - \\
\hline & S4 & & $\mathrm{R} 2$ & R5 - & & $\mathrm{R} 8$ & & $\mathrm{R} 12+$ & $\mathrm{R} 18+$ & $\mathrm{R} 22+$ & $\mathrm{R} 24+$ \\
\hline \multirow{3}{*}{ 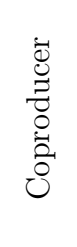 } & S5 & \multirow[t]{3}{*}{-} & R3 & R6 - & - & - & - & $\mathrm{R} 13+$ & - & - & - \\
\hline & S6 & & - & - & - & - & - & $\mathrm{R} 14+$ & $\mathrm{R} 19+$ & - & - \\
\hline & S7 & & - & - & - & - & - & $\mathrm{R} 15+$ & $\mathrm{R} 20+$ & - & $\mathrm{R} 25+$ \\
\hline
\end{tabular}

S1-Demand for faster and more integrated public e-services

S2 - Willingness to pay extra money for faster and more integrated public e-services

S3-Willingness to take time to consult relevant information

$\mathrm{S} 4$ - Willingness to take time to participate in the democratic processes through an online platform

S5-Willingness to favor the use of public e-services if it reduces government's administrative burden

S6-Willingness to take time to send relevant information

S7-Willingness to take time to participate in the development of public e-services

* - - Respondents with lower values of the independent variable (factor) tend to have higher values for the dependent variable (statement)

+ - Respondents with higher values of the independent variable (factor) tend to have higher values for the dependent variable (statement) 


\section{Discussion}

\subsection{Limitations}

The first limitation stems from the three roles and the derived set of statements we used to develop the elicit the expectations from citizens. Other frameworks that structure the roles of citizens in digital government exist. For instance, the typology of Distel and Lindgren 2019] structures the citizens into six user types: minimal user, power user, communicative user, pragmatic user, goal-oriented occasional user, and versatile occasional user. The structure of the questionnaire and the questions about the expectations could have been adapted according to such a typology.

Furthermore, due to the exploratory nature of this work, we examined the influence of several factors we selected from related literature on expectations but other factors could have been studied as well, such as the perceived quality of public services for instance. However, including additional factors in this study would have made our questionnaire longer to complete and potentially decreased the quality of the collected responses Malhotra, 2008, which could have deterred some citizens from answering. Therefore, we limited our study to ten factors and left the others for future research. In Section 5.2 we provide research leads to undertake research in this direction. Lastly, our study was performed on a sample of citizens in Belgium. As shown in Table 2, our sample overall matches the distribution of the Belgian population but further research is needed to ensure generalization of the findings through a large scale validation study. Despite the local character of this study, it still delivers relevant implications for research and practice.

\subsection{Implications for Research}

In this paper, we have explored which factors impact the expectations of citizens regarding digital government. The studied factors include the government level, citizens' socio-economic characteristics, digital literacy, and e-service use frequency. Even though our research design drew from previous studies as mentioned in Section 2, the studied relationships were not explored in previous research and opens the way for future endeavors. Below, we present three directions for future work we identified. We discuss their relevance and provide leads for researchers interested in addressing them.

First, the quantitative analysis reported in this paper, although already providing interesting insights, could be enriched with qualitative data following a mixed-methods approach [Johnson et al., 2007]. One possibility would be to set the focus on one sub-category of the population and to study its expectations more in depth. Another way forward would be to dig deeper into one of the three roles, in order to confirm the influences of the studied factors we observed for the role at hand, and to understand why they exist. The factors for which our analysis revealed a significant difference across respondents groups but for which the post-hoc analysis could not yield any additional insight would be especially interesting to study deeper.

Second, the survey can be used to identify key citizen profiles in the population with a bundle of similar expectations. Such an analysis was performed in Distel and Becker, 2017] but was left out in our study. These profiles could then guide the elaboration of personas (i.e. descriptions of fictive users guiding design) to help public agents to take into account the requirements of different citizen groups when developing digital government services. 
Literature has highlighted several approaches to identifying citizen profiles from quantitative data that could be used with the data we collected such as pattern coding [Saldaña, 2015], parralel coordinates plot [Johansson et al., 2008] or clustering algorithm [Saxena et al., 2017].

Third, It would be interesting to compare the results for Belgium with other countries. Such an international comparison would be useful, and needed, to understand the willingness of citizens to take on roles in digital government at the European level, where citizens from many different countries deal with the same digital government implementation. This would refine our research model with additional factors, such as the impact of national culture Hofstede, 1991.

\subsection{Implications for Practice}

This study also has implications for practice as the questionnaire we designed constitutes an easy-to-use survey tool to understand the requirements of citizens regarding digital government. Thanks to our thorough description of the data instrument and analysis, public servants can build on this research to better understand their population and adapt the digitalization of government accordingly. Depending on the distribution of the expectations, the policy-makers can adapt the digital government strategy so that it is customer-oriented, participation-oriented, or coproducer-oriented. In order to provide a better support to policymakers, the data collected through our questionnaire could be presented to them visually, to ease the extraction of insights. The interest of offering information visualizations to policymakers has been underlined by previous literature [Ruppert et al., 2015]. One possibility would be to plot the median of the responses to the seven statements on a radar chart, in order to have a quick overview of citizens' responses. Comparison between citizen groups could also be performed by generating one radar chart per group. For example, Figure 2 shows such radar charts generated from our data for students, employed, and retired citizens. The comparison of the three radar charts quickly shows that the three occupation groups are similar in their responses, except for retired citizens who tend disagree more with S2 (pay for better services) and S4 (democratic processes).

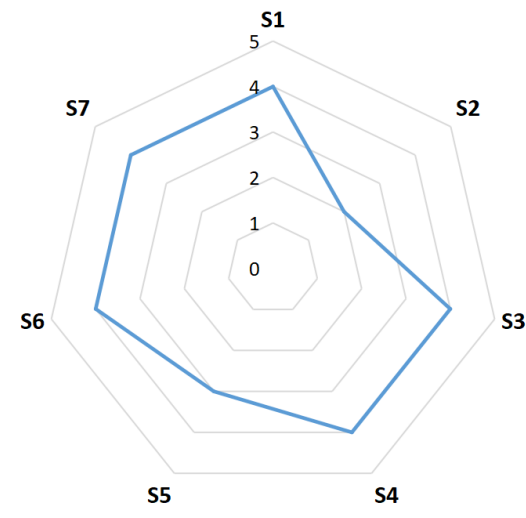

(a) Students

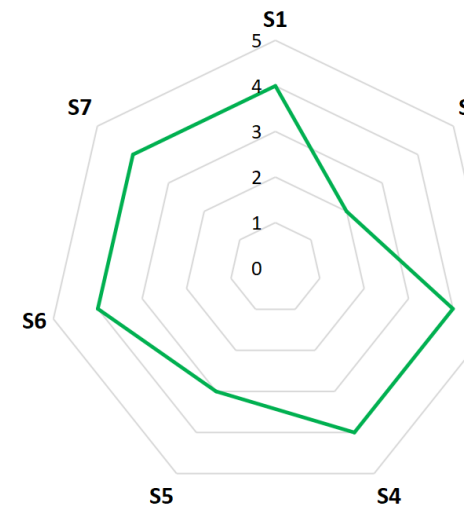

(b) Employed

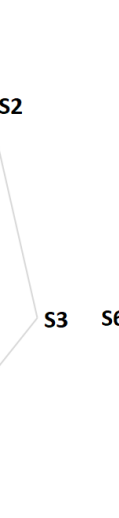

Figure 2: Radar charts representing the median of the answers given to the seven statements by students, employed, and retired citizens

Once the expectations for a given population are identified, a logical next step would be to link best practices from digital governments around the world to meet each these 
expectations so that policy-makers can design policies based on best practices, targeted for their population. We here suggest some leads for several relationships we identified from our analyses:

In $\mathbf{R 2}$, we found out that males were more willing to take time to participate in the online democratic processes. This is consistent with the gender gap identified by Vicente and Novo 2014 in the context of e-participation. Having this information, a policy-maker could organize offline sessions dedicated to women or collect requirements from them to understand why they are less willing to participate in the democratic processes, and thus adapt online democratic process accordingly. The same reasoning applies for the discrepancies in age groups from $\mathbf{R} 5$.

In R9-R15, we found out that the fragment of the population with higher digital literacy had higher expectations towards digital government. Indeed, in order to get deeper insights into the expectations of he respondents having a lower digital literacy, we conducted an analysis focused on the 36 having a digital literacy score of $2 / 5$ or less. Overall, they are in demand of faster and more integrated public e-services and they are willing to use such services to consult information, to participate in democratic processes, and to send information. However, they are not willing to pay extra money for this. Regarding the willingness to contribute to reducing the government's administrative load, there is no clear tendency. Finally, approximately $25 \%$ of the 36 respondents are willing to participation in the development of these services, compared to $61 \%$ for the other respondents. These findings are alike for the local and the federal/regional government level. The respondents with lower reported digital literacy would thus be more difficult to mobilize to participate in the development of digital government services. It should therefore be the responsibility of the governments to perform proactive actions to collect their input in an inclusive manner to ensure that they are aligned with their needs. The use of focus groups and crowd-centric requirements engineering platforms to crowdsource the requirements engineering task in a user-friendly manner, using gamification for instance, would constitute way forwards to achieve this Snijders et al. 2015. Regarding citizens with a higher digital literacy we would suggest policymakers to consider these citizens as lead users [Von Hippel, 1986] and to include them in reflections related to digital transformation.

In R19, we found out that citizens who use private e-services more frequently were more willing to send information to their government via a dedicated application. As the boundary between private and public e-services is becoming less distinct Lindgren and Jansson, 2013], a policy-maker could identify the features of private e-services that drive the citizens to use them and incorporate them into the developed application.

\section{Conclusion}

In order to address our main research question, we have developed an exploratory survey instrument to understand the roles citizens are willing to take in a digital government and the factors that influence them. These expectations are measured with seven statements, derived from three roles citizens can take in digital government: citizens as customers, as 
participants, and as coproducers. The factors we investigated are the gender, the age, the occupation, the education level, the use of other electronic services, the digital literacy, and the government level.

Using this instrument, we collected data from 203 citizens in Belgium, we have identified 25 relationships between the studied factors and citizens' expectations. We have identified relationships between expectations and government level, gender, age, occupation, use frequency of other e-services, and digital literacy. The main factors impacting the roles citizens are willing to take are the digital literacy ( 7 relationships) and the private e-service use (5 relationships).

The study allows researchers to build upon the identified relationships in further research as they are novel in the field and provides them a tested research instrument to identify these expectations. This study also allows policy-makers to adapt their digital government strategy, drawing insights from the results of the survey.

This study opens several avenues for further research. First, our approach could be enriched by collecting qualitative data. This would make it possible to dig deeper into one factor or one citizen group. Second, our data could be used to identify citizen profiles that could guide public servants in analyzing citizens' requirements. Third, more factors could be included to study the impact of culture and collect useful insights for digital government implementations at the international level. Furthermore, we explain how the exploration of the expectations can act as a governance tool and help policy-makers to improve their digital government strategy. Indeed, through simple statistics that can be presented as a dashboard, policy-makers can identify the expectations of the population and adapt the strategy so that it is aligned with its needs. Through the analysis of the relationships between factors and expectations, policy-makers can implement more targeted policies thanks to the fine-grained knowledge acquired.

\section{References}

Ahmad, M.O., Markkula, J., Oivo, M. (2013), "Factors affecting e-government adoption in pakistan: a citizen's perspective", Transforming Government: People, Process and Policy, Vol. 7 No. 3, pp. 225-239.

Alenezi, H., Tarhini, A., Masa'deh, R., Alalwan, A., Al-Qirim, N. (2017), "Factors affecting the adoption of e-government in kuwait: A qualitative study", Electronic Journal of eGovernment, Vol. 15 No. 2, pp. 84-102.

Andersen, K.V., Henriksen, H.Z. (2006), "E-government maturity models: Extension of the layne and lee model", Government Information Quarterly, Vol. 23 No. 2, pp. 236-248.

Arnstein, S.R. (1969), "A ladder of citizen participation", Journal of the American Institute of Planners, Vol. 35 No. 4, pp. 216-224.

Axelsson, K., Melin, U., Lindgren, I. (2010), "Exploring the importance of citizen participation and involvement in e-government projects", Transforming Government: People, Process and Policy, Vol. 4 No. 4, pp. 299-221. 
Bache, I., Bartle, I., Flinders, M. (2016), "Multi-level governance", in Ansell, C., Torfing, J. (Eds.), Handbook on theories of governance, Edward Elgar Publishing, Northampton, pp. 486-498.

Baldwin, J.N., Gauld, R., Goldfinch, S. (2012), "What public servants really think of egovernment", Public Management Review, Vol. 14 No. 1, pp. 105-127.

Bélanger, F., Carter, L. (2008), "Trust and risk in e-government adoption", The Journal of Strategic Information Systems, Vol. 17 No. 2, pp. 165-176.

Bélanger, F., Carter, L. (2009), "The impact of the digital divide on e-government use", Communications of the ACM, Vol. 52 No. 4, pp. 132-135.

Berntzen, L., Johannessen, M.R. (2016), "The role of citizen participation in municipal smart city projects: Lessons learned from norway", in Gil-Garcia, J.R., Pardo, T.A., Nam, T. (Eds.), Smarter as the new urban agenda, Springer, Cham, pp. 299-314.

Bewick, V., Cheek, L., Ball, J. (2004), "Statistics review 10: further nonparametric methods", Critical Care, Vol. 8 No. 3, pp. 196.

Callahan, K. (2007), "Citizen participation: Models and methods", International Journal of Public Administration, Vol. 30 No. 11, pp. 1179-1196.

Choi, J.C., Song, C. (2020), "Factors explaining why some citizens engage in e-participation, while others do not", Government Information Quarterly, Vol. 37 No. 4, pp. 101524.

Cronbach, L.J. (1951), "Coefficient alpha and the internal structure of tests", Psychometrika, Vol. 16 No. 3, pp. 297-334.

Distel, B., Becker, J. (2017), "All citizens are the same, aren't they?-developing an egovernment user typology", in Proceedings of the 2017 International Conference on Electronic Government, Springer, pp. 336-347.

Distel, B., Lindgren, I. (2019), "Who are the users of digital public services?", in Proceedings of the International Conference on Electronic Participation, Springer, pp. 117-129.

Dunn, O.J. (1961), "Multiple comparisons among means", Journal of the American Statistical Association, Vol. 56 No. 293, pp. 52-64.

Etikan, I., Musa, S.A., Alkassim, R.S. (2016), "Comparison of convenience sampling and purposive sampling", American Journal of Theoretical and Applied Statistics, Vol. 5 No. 1, pp. 1-4.

Eyob, E. (2004), "E-government: breaking the frontiers of inefficiencies in the public sector", Electronic Government, an International Journal, Vol. 1 No. 1, pp. 107-114.

Foley, P., Alfonso, X. (2009), "egovernment and the transformation agenda", Public Administration, Vol. 87 No. 2, pp. 371-396. 
Gaddis, G.M., Gaddis, M.L. (1990), "Introduction to biostatistics: Part 5, statistical inference techniques for hypothesis testing with nonparametric data", Annals of Emergency Medicine, Vol. 19 No. 9, pp. 1054-1059.

Gil-Garcia, J.R., Dawes, S.S., Pardo, T.A. (2018), "Digital government and public management research: finding the crossroads", Public Management Review, Vol. 20 No. 5, pp. 633-646.

Gilbert, D., Balestrini, P., Littleboy, D. (2004), "Barriers and benefits in the adoption of e-government", International Journal of Public Sector Management, Vol. 17 No. 4, pp. $286-301$.

Hamid, A.A., Razak, F.Z.A., Bakar, A.A., Abdullah, W.S.W. (2016), "The effects of perceived usefulness and perceived ease of use on continuance intention to use e-government", Procedia Economics and Finance, Vol. 35 No. 2016, pp. 644-649.

Hargittai, E. (2005), "Survey measures of web-oriented digital literacy", Social Science Computer Review, Vol. 23 No. 3, pp. 371-379.

Hargittai, E. (2009), "An update on survey measures of web-oriented digital literacy", Social Science Computer Review, Vol. 27 No. 1, pp. 130-137.

Hargittai, E., Hsieh, Y.P. (2012), "Succinct survey measures of web-use skills", Social Science Computer Review, Vol. 30 No. 1, pp. 95-107.

Hofstede, G. (1991), Cultures and organizations : software of the mind, McGraw-Hill, London.

Horst, M., Kuttschreuter, M., Gutteling, J.M. (2007), "Perceived usefulness, personal experiences, risk perception and trust as determinants of adoption of e-government services in the netherlands", Computers in Human Behavior, Vol. 23 No. 4, pp. 1838-1852.

Hung, S.Y., Chang, C.M., Yu, T.J. (2006), "Determinants of user acceptance of the egovernment services: The case of online tax filing and payment system", Government Information Quarterly, Vol. 23 No. 1, pp. 97-122.

Janssen, M., Charalabidis, Y., Zuiderwijk, A. (2012), "Benefits, adoption barriers and myths of open data and open government", Information Systems Management, Vol. 29 No. 4, pp. 258-268.

Jaspers, S., Steen, T. (2019), "Realizing public values: enhancement or obstruction? exploring value tensions and coping strategies in the co-production of social care", Public Management Review, Vol. 21 No. 4, pp. 606-627.

Johansson, J., Forsell, C., Lind, M., Cooper, M. (2008), "Perceiving patterns in parallel coordinates: determining thresholds for identification of relationships", Information Visualization, Vol. 7 No. 2, pp. 152-162. 
Johnson, R.B., Onwuegbuzie, A.J., Turner, L.A. (2007), "Toward a definition of mixed methods research", Journal of Mixed Methods Research, Vol. 1 No. 2, pp. 112-133.

Jonckheere, A.R. (1954), "A distribution-free k-sample test against ordered alternatives", Biometrika, Vol. 41 No. 1/2, pp. 133-145.

Kaur, J., Rashid, N.D.N. (2008), "Malaysian electronic government adoption barriers", Public Sector ICT Management Review, Vol. 2 No. 1, pp. 38-43.

Kruskal, W.H., Wallis, W.A. (1952), "Use of ranks in one-criterion variance analysis", Journal of the American Statistical Association, Vol. 47 No. 260, pp. 583-621.

Kumar, V. (2014), "Making "freemium" work", Harvard Business Review, Vol. 92 No. 5, pp. $27-29$.

Kurfalı, M., Arifoğlu, A., Tokdemir, G., Paçin, Y. (2017), "Adoption of e-government services in turkey", Computers in Human Behavior, Vol. 66 No. 1, pp. 168-178.

Lawson-Body, A., Illia, A., Willoughby, L., Lee, S. (2014), "Innovation characteristics influencing veterans' adoption of e-government services", Journal of Computer Information Systems, Vol. 54 No. 3, pp. 34-44.

Linders, D. (2012), "From e-government to we-government: Defining a typology for citizen coproduction in the age of social media", Government Information Quarterly, Vol. 29 No. 4, pp. 446-454.

Lindgren, I., Jansson, G. (2013), "Electronic services in the public sector: A conceptual framework", Government Information Quarterly, Vol. 30 No. 2, pp. 163-172.

Macintosh, A. (2004), "Characterizing e-participation in policy-making", in Proceedings of the 2004 Hawaii International Conference on System Sciences, IEEE, pp. 1-10.

Malhotra, N. (2008), "Completion time and response order effects in web surveys", Public Opinion Quarterly, Vol. 72 No. 5, pp. 914-934.

Malhotra, N., Décaudin, J.M., Bouguerra, A., Bories, D. (2011), Etudes marketing (6th ed.), Pearson Éducation, Paris.

Meftah, M., Gharleghi, B., Samadi, B. (2015), "Adoption of e-government among bahraini citizens", Asian Social Science, Vol. 11 No. 4, pp. 141.

Naranjo-Zolotov, M., Oliveira, T., Cruz-Jesus, F., Martins, J., Gonçalves, R., Branco, F., Xavier, N. (2019), "Examining social capital and individual motivators to explain the adoption of online citizen participation", Future Generation Computer Systems, Vol. 92 No. 1, pp. 302-311.

Nawafleh, S. (2018), "Factors affecting the continued use of e-government websites by citizens", Transforming Government: People, Process and Policy, Vol. 12 No. 3/4, pp. 244264. 
Pak, B., Chua, A., Vande Moere, A. (2017), "Fixmystreet brussels: socio-demographic inequality in crowdsourced civic participation", Journal of Urban Technology, Vol. 24 No. 2, pp. 65-87.

Peterson, R.A. (1994), "A meta-analysis of cronbach's coefficient alpha", Journal of Consumer Research, Vol. 21 No. 2, pp. 381-391.

Porwol, L., Ojo, A., Breslin, J.G. (2016), "An ontology for next generation e-participation initiatives", Government Information Quarterly, Vol. 33 No. 3, pp. 583-594.

Pratt, J.W., Gibbons, J.D. (1981), "Kolmogorov-smirnov two-sample tests", in Concepts of nonparametric theory, Springer, New-York, pp. 318-344.

Rodrigues, G., Sarabdeen, J., Balasubramanian, S. (2016), "Factors that influence consumer adoption of e-government services in the uae: A utaut model perspective", Journal of Internet Commerce, Vol. 15 No. 1, pp. 18-39.

Ruppert, T., Dambruch, J., Krämer, M., Balke, T., Gavanelli, M., Bragaglia, S., Chesani, F., Milano, M., Kohlhammer, J. (2015), "Visual decision support for policy making: advancing policy analysis with visualization", in Janssen, M., Wimmer, M.A., Deljoo, A. (Eds.), Policy Practice and Digital Science, Springer, Cham, pp. 321-353.

Saldaña, J. (2015), The coding manual for qualitative researchers, Sage, London.

Saxena, A., Prasad, M., Gupta, A., Bharill, N., Patel, O.P., Tiwari, A., Er, M.J., Ding, W., Lin, C.T. (2017), "A review of clustering techniques and developments", Neurocomputing, Vol. 267 No. 1, pp. 664-681.

Schober, P., Boer, C., Schwarte, L.A. (2018), "Correlation coefficients: appropriate use and interpretation", Anesthesia \& Analgesia, Vol. 126 No. 5, pp. 1763-1768.

Simonofski, A., Asensio, E.S., De Smedt, J., Snoeck, M. (2017), "Citizen participation in smart cities: Evaluation framework proposal", in Proceedings of the 2017 IEEE Conference on Business Informatics, IEEE, pp. 227-236.

Simonofski, A., Chantillon, M., Crompvoets, J., Vanderose, B., Snoeck, M. (2020), "The influence of public values on user participation in e-government: An exploratory study", in Proceedings of the 2020 Hawaii International Conference on System Sciences, IEEE, pp. 227-236.

Simonofski, A., Snoeck, M., Vanderose, B. (2019), "Co-creating e-government services: An empirical analysis of participation methods in belgium", in Bolivar, M.P.R. (Ed.), Setting Foundations for the Creation of Public Value in Smart Cities, Springer, Cham, pp. 225245.

Simonofski, A., Snoeck, M., Vanderose, B., Crompvoets, J., Habra, N. (2017), "Reexamining e-participation: Systematic literature review on citizen participation in e-government service delivery", in Proceedings of the 2017 Americas Conference on Information Systems, pp. $1-10$. 
Snijders, R., Atilla, Ö., Dalpiaz, F., Brinkkemper, S.. (2015). "Crowd-centric requirements engineering: A method based on crowdsourcing and gamification".

Spearman, C. (1961), "The proof and measurement of association between two things", in Jenkins, J.J., Paterson, D.G. (Eds.), Studies in individual differences: The search for intelligence, Appleton-Century-Crofts, New-York, pp. 45-58.

Sundberg, L. (2019), "Electronic government: Towards e-democracy or democracy at risk?", Safety Science, Vol. 118 No. 1, pp. 22-32.

Terpstra, T.J. (1952), "The asymptotic normality and consistency of kendall's test against trend, when ties are present in one ranking", Indagationes Mathematicae, Vol. 14 No. 3, pp. 327-333.

Tolbert, C.J., Mossberger, K. (2006), "The effects of e-government on trust and confidence in government", Public Administration Review, Vol. 66 No. 3, pp. 354-369.

Veiga, L., Janowski, T., Barbosa, L.S. (2016), "Digital government and administrative burden reduction", in Proceedings of the 2016 International Conference on Theory and Practice of Electronic Governance, pp. 323-326.

Vicente, M.R., Novo, A. (2014), "An empirical analysis of e-participation. the role of social networks and e-government over citizens' online engagement", Government Information Quarterly, Vol. 31 No. 3, pp. 379-387.

Von Hippel, E. (1986), "Lead users: a source of novel product concepts", Management Science, Vol. 32 No. 7, pp. 791-805.

Voutinioti, A. (2013), "Determinants of user adoption of e-government services in greece and the role of citizen service centres", Procedia Technology, Vol. 8 No. 1, pp. 238-244.

West, D.M. (2005), Digital government: Technology and public sector performance, Princeton University Press, Princeton.

Wijnhoven, F., Ehrenhard, M., Kuhn, J. (2015), "Open government objectives and participation motivations", Government Information Quarterly, Vol. 32 No. 1, pp. 30-42.

Yildiz, M. (2007), "E-government research: Reviewing the literature, limitations, and ways forward", Government Information Quarterly, Vol. 24 No. 3, pp. 646-665. 


\section{Appendix - Statistic tests details}

Table 4: Statistic tests details

\begin{tabular}{|c|c|}
\hline Relationship & Statistic value and significance level \\
\hline \multirow{2}{*}{ R1 } & loc: $\mathrm{K}-\mathrm{S}=1.702, \mathrm{p}=0.006$ \\
\hline & fed: $\mathrm{K}-\mathrm{S}=1.497, \mathrm{p}=0.023$ \\
\hline \multirow{2}{*}{$\mathrm{R} 2$} & loc: $\mathrm{K}-\mathrm{S}=1.809, \mathrm{p}=0.003$ \\
\hline & fed: $\mathrm{K}-\mathrm{S}=1.388, \mathrm{p}=0.042$ \\
\hline R3 & loc: $\mathrm{K}-\mathrm{S}=1.367, \mathrm{p}=0.048$ \\
\hline \multirow{2}{*}{$\mathrm{R} 4$} & loc: $\mathrm{J}=6620.000$, std. $\mathrm{J}=-2.931, p=0.003$ \\
\hline & fed: $J=6409.000$, std. $J=-3.415, p=0.001$ \\
\hline \multirow{2}{*}{ R5 } & loc: $J=6640.000$, std. $J=-2.879, p=0.004$ \\
\hline & fed: $J=6506.500$, std. $J=-3.204, p=0.001$ \\
\hline R6 & fed: $J=7017.500$, std. $J=-1.979, p=0.048$ \\
\hline \multirow{2}{*}{$\mathrm{R} 7$} & loc: $\mathrm{H}=14.636, \mathrm{p}=0.002$ \\
\hline & fed: $H=10.771, p=0.013$ \\
\hline \multirow{2}{*}{$\mathrm{R} 8$} & loc: $\mathrm{H}=11.475, \mathrm{p}=0.009$ \\
\hline & fed: $H=13.427, p=0.004$ \\
\hline \multirow{2}{*}{ R9 } & loc: $J=9206.500$, std. $J=5.639, p=0.000$ \\
\hline & fed: $J=9218.500$, std. $J=5.927, p=0.000$ \\
\hline R10 & loc: $J=8055.000$, std. $J=2.179, p=0.029$ \\
\hline \multirow[t]{2}{*}{ R11 } & loc: $J=8328.500$, std. $J=2.691, p=0.007$ \\
\hline & fed: $J=8079.000$, std. $J=3.644, p=0.000$ \\
\hline \multirow{2}{*}{$\mathrm{R} 12$} & loc: $\mathrm{J}=9655.500$, std. $\mathrm{J}=5.453, \mathrm{p}=0.000$ \\
\hline & fed: $J=9192.000$, std. $J=4.626, p=0.000$ \\
\hline $\mathrm{R} 13$ & fed: $J=8706.500$, std. $J=2.140, p=0.032$ \\
\hline \multirow{2}{*}{ R14 } & loc: $J=8344.000$, std. $J=4.208, p=0.000$ \\
\hline & fed: $J=8763.500$, std. $J=4.825, p=0.000$ \\
\hline \multirow{2}{*}{$\mathrm{R} 15$} & loc: $J=9856.000$, std. $J=5.028, p=0.000$ \\
\hline & fed: $J=9180.500$, std. $J=4.199, p=0.000$ \\
\hline
\end{tabular}

loc - local government level

fed - federal/regional government level

$\mathrm{p}$ - p-value

K-S - Kolmogorov-Smirnov test statistic

$\mathrm{J}$ - Jonckheere-Terpstra test statistic

std. J - standardized Jonckheere-Terpstra test statistic

$\mathrm{H}$ - Kruskal-Wallis test statistic 
Table 5: Statistic tests details (continued)

\begin{tabular}{|c|c|}
\hline Relationship & Statistic value and significance level \\
\hline \multirow{2}{*}{$\mathrm{R} 16$} & loc: $\mathrm{J}=8661.000$, std. $\mathrm{J}=4.463, \mathrm{p}=0.000$ \\
\hline & fed: $\mathrm{J}=8122.500$, std. $\mathrm{J}=3.179, \mathrm{p}=0.001$ \\
\hline \multirow{2}{*}{$\mathrm{R} 17$} & loc: $\mathrm{J}=7959.000$, std. $\mathrm{J}=2.743, \mathrm{p}=0.006$ \\
\hline & fed: $J=8042.500$, std. $J=3.049, p=0.002$ \\
\hline $\mathrm{R} 18$ & fed: $J=7662.000$, std. $J=2.040, p=0.041$ \\
\hline \multirow{2}{*}{ R19 } & loc: $\mathrm{J}=8337.000$, std. $\mathrm{J}=3.744, \mathrm{p}=0.000$ \\
\hline & fed: $J=8332.000$, std. $Z=3.714, p=0.000$ \\
\hline \multirow{2}{*}{$\mathrm{R} 20$} & loc: $J=8164.500$, std. $J=3.130, p=0.002$ \\
\hline & fed: $J=7764.500$, std. $J=2.260, p=0.024$ \\
\hline \multirow{2}{*}{$\mathrm{R} 21$} & loc: $\mathrm{J}=4792.000$, std. $\mathrm{J}=2.517, \mathrm{p}=0.012$ \\
\hline & fed: $J=4635.500$, std. $J=2.049, p=0.040$ \\
\hline \multirow{2}{*}{$\mathrm{R} 22$} & loc: $\mathrm{J}=4819.500$, std. $\mathrm{J}=2.561, \mathrm{p}=0.010$ \\
\hline & fed: $J=4996.500$, std. $J=3.112, p=0.002$ \\
\hline $\mathrm{R} 23$ & fed: $J=7033.500$, std. $J=2.523, p=0.012$ \\
\hline \multirow{2}{*}{$\mathrm{R} 24$} & loc: $\mathrm{J}=7116.000$, std. $\mathrm{J}=2.678, \mathrm{p}=0.007$ \\
\hline & fed: $J=7142.000$, std. $J=2.760, p=0.006$ \\
\hline $\mathrm{R} 25$ & fed: $J=6890.500$, std. $J=2.114, p=0.035$ \\
\hline
\end{tabular}

loc - local government level

fed — federal/regional government level

$\mathrm{p}$ - p-value

K-S - Kolmogorov-Smirnov test statistic

$\mathrm{J}$ - Jonckheere-Terpstra test statistic

std. J - standardized Jonckheere-Terpstra test statistic

$\mathrm{H}$ - Kruskal-Wallis test statistic 